\title{
Fiberoptic Endoscopy: The Singular Transformative Event of Our Time
}

\author{
C. Mel Wilcox
}

Published online: 4 September 2014

(c) Springer Science+Business Media New York 2014

Thousands of manuscripts are published each week, and there continues to be a vast wave of new journals becoming available almost daily for the dissemination of new knowledge. Yet, almost all advances in medicine are incremental. By contrast, revolutionary advances, which change the natural history of disease or alter clinical practice, are quite rare. One such event was the development and widespread adoption of fiberoptic endoscopy, which forever altered the science, and practice of gastroenterology.

In this issue of the Journal, Dr. Kaunitz [1] chronicles the timeline of the development of the endoscope from the rigid instruments to the early flexible fiberoptic endoscope, highlighting the major milestones and contributions from legends such as Rudolph Schindler and Basil Hirschowitz and the skills and ingenuity that they possessed. Building upon this historical background, I will review fiberoptic endoscopy in the context of its impact on current clinical practice and societal health. Several common themes throughout this journey are that we had to wait for technology to catch up with our interventional dreams, and the profound effect endoscopy has had not only on our practice but also on other specialties, especially surgery. I will make the case that fiberoptic endoscopy was the singular transformative event of the last century for our specialty.

C. M. Wilcox $(\square)$

Division of Gastroenterology and Hepatology, Basil I.

Hirschowitz Endoscopic Center of Excellence, University of

Alabama at Birmingham, 1720 2nd Ave., South, BDB 380,

Birmingham, AL 35294-0113, USA

e-mail:melw@uab.edu

\section{From Inspection to Palpation}

Early pioneers attempting to visualize the gastrointestinal (GI) tract passionately desired to directly inspect the GI mucosa. The original instruments, as highlighted by Dr. Kaunitz, were rigid, difficult to use, and failed to visualize the proximal stomach and duodenal bulb which are important areas of pathology. Instrument flexibility provided by fiberoptic endoscopy improved visualization and clarity such that these "blind spots" in the upper GI tract could now be directly inspected [2]. A major technologic advancement of second-generation models, initially available in 1963, was end-viewing rather than side-viewing capability (Fig. 1) that was a key to examining tubular structures like the esophagus. An end-viewing instrument also facilitated the development of an open channel that could be used not only for aspiration but also for passing instruments such as biopsy forceps. Other advances included a separate light bundle with an external light source for improved illumination as well as a washing device to clean the lens. This was then the beginning of a remarkable journey yielding major advances in our understanding of GI disease, which lead ultimately to alterations in the natural history of disease and new avenues of therapy.

The ability to perform mucosal biopsy and its utility cannot be overstated. Although this common procedure seems trivial now, the capacity to biopsy tissue has been the basis for many of the subsequent gains in knowledge and use in clinical practice. I wonder what these original endoscopists felt as they could actually watch a biopsy being performed and wondering if the subtle bleeding would stop. The ability to biopsy has been critical for patient management including diagnosing infections (of major importance for immunosuppressed patients), cancer, as well as distinguishing the types of inflammatory bowel disease. 


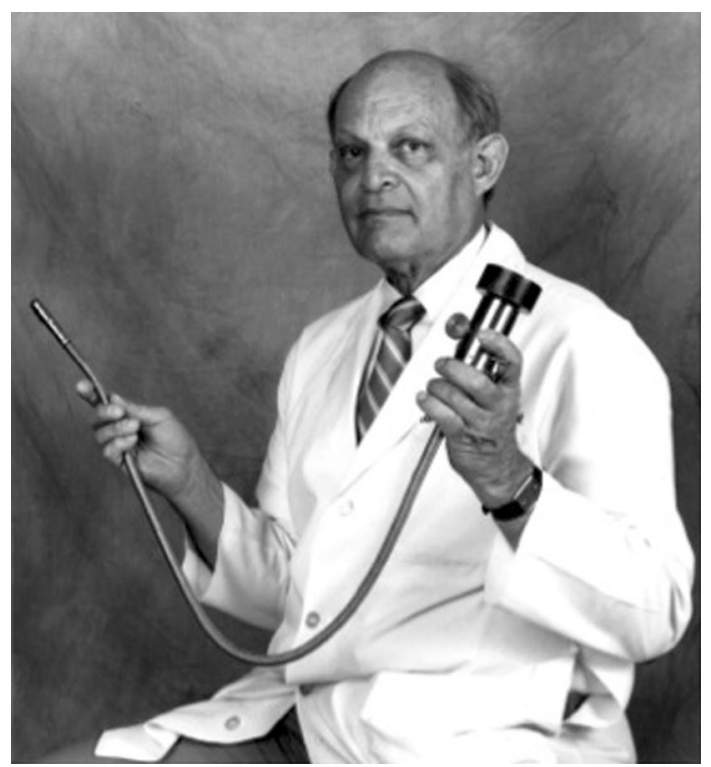

Fig. 1 Dr. Basil Hirschowitz with his early fiberscope. Note that unlike most current endoscopes, it is a side-viewing instrument (photo courtesy of Dr. Basil Hirschowitz)

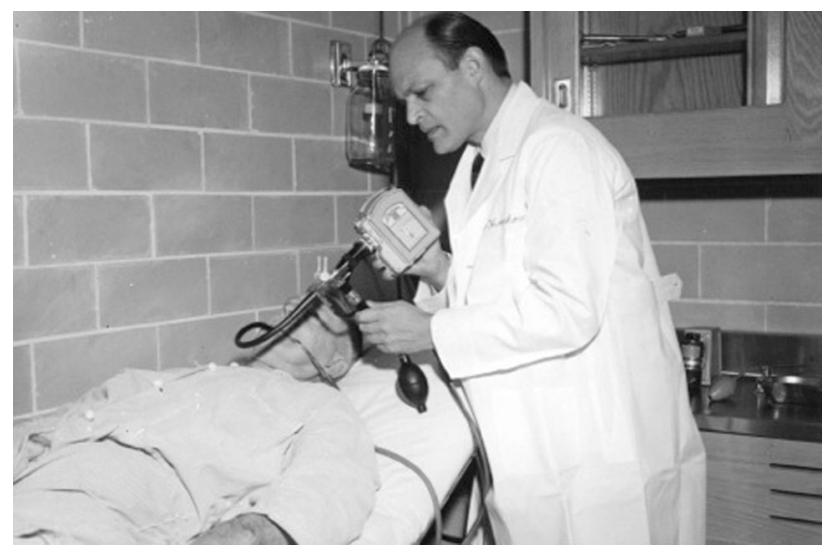

Fig. 2 Dr. Hirschowitz using an endo-camera in order to make endoscopic photographs. This instrument is an early forerunner of the video endoscope (photo courtesy of Dr. Basil Hirschowitz)

Initially, endoscopic research was principally descriptive [3]. Photography, albeit primitive by current standards, soon became available, opening the door to share images [4] (Fig. 2). A classic descriptive study documented stigmata of bleeding ulcers and their natural history, specifically the visible vessel [5]. Such seemingly simple observations paved the way for subsequent endoscopic therapeutic trials that then focused on these high-risk lesions.

Over the years, further improvements in the endoscopes themselves (smaller size, greater flexibility, and ease of use) expanded endoscopy worldwide to budding endoscopists and patients alike. We have also progressed from fiberoptics to video systems dramatically enhancing opportunities for visualization, teaching, and improving the ease of doing endoscopy. We have also taken advantage of the properties of light to enhance visualization. Standard white light technology has now been expanded to multiple modalities that can better characterize lesions and, in fact, now potentially provide endoscopic histology (optical tissue biopsy) [6-8]. These emerging technologies include narrowband imaging which enhance the mucosal vascular pattern that is abnormal in neoplastic tissue [9]. Standard white light can now be magnified for high-resolution again better characterizing lesions. Endomicroscopy uses a low power laser to illuminate tissue and may, in fact, avoid biopsy when used to survey Barrett's esophagus [8].

\section{From Diagnostic to Therapeutic}

Therapy is the ultimate goal of endoscopy. What formerly was a dream is now the standard of care. Although diagnostic endoscopy provided useful data, it alone was not of major benefit for patients with significant bleeding ulcer $[10,11]$. Although one could predict which ulcers would re-bleed and establish or diagnose the cause of bleeding better than what was available with contrast radiology, without therapy, endoscopic diagnosis provided no benefit in terms of overall outcomes [11, 12]. Such therapy can now be applied to bleeding ulcers and esophageal varices, reducing transfusion requirements, the need for surgery, and ultimately mortality $[13,14]$.

The discovery that Helicobacter pylori contributed to the pathogenesis of peptic ulcer disease revolutionized gastroenterology practice [15]. For decades, peptic ulcer disease was a major cause of morbidity and mortality, and had been a primary focus for the general surgeon [16]. Peptic ulcer surgery is now a curiosity encountered mostly in textbooks or in those whose disease predated this discovery [17].

The ability to ablate and remove lesions, relieve obstruction, or find cancers with a variety of tools has changed practice for gastroenterologists, surgeons, and oncologists. Endoscopic ablative technologies including laser or radiofrequency ablation can remove high-grade dysplasia or early cancer that was at one time only amenable to surgical treatment [18, 19]. Endosocpically deployed stents for obstructing upper and lower GI cancers achieve good palliation while avoiding the potential mortality of surgical bypass.

Several major advances to endoscopic technology themselves have been revolutionary. Three such developments include the therapeutic side-viewing endoscope, 
endoscopic ultrasonography (EUS), and imaging of the small bowel with both capsule and subsequently single and double balloon endoscopy. Although endoscopic retrograde cholangiopancreatography (ERCP) was first performed in the early 1970s [18], the technique acquired therapeutic potential over the ensuing three decades. For example, endoscopic stone extraction obviated the need for surgical common bile duct exploration with its associated morbidity. Fortunately and serendipitously, the development of therapeutic ERCP paralleled that of the development of laparoscopy, enabling the endoscopic removal of common bile duct stones and the repair of amelioration of strictures and leaks that more frequently complicated laparoscopic than open cholecystectomy [20, 21]. The availability of endoscopic stenting for neoplastic biliary obstruction, transformed treatment, with endoscopic therapy reported superior to surgical on the basis of randomized trials [22].

The development of EUS improved the evaluation of mucosal lesions and organs surrounding the esophagus, stomach, duodenum, and rectum, making possible the endoscopic biopsy of mediastinal lymph nodes or pancreatic lesions, which was unimaginable 20 years ago. Comparable to endoscopy in general, EUS has evolved from a diagnostic to a therapeutic procedure, with the capability, for example, of draining pancreatic pseudocysts or transgastric bile duct puncture or stenting, supplanting surgical approaches [23, 24]. The ability to directly visualize the entire small bowel promises to provide less morbid ways to diagnose and treat intestinal pathology $[25,26]$.

\section{From Therapeutics to Cure}

Surveillance has positively impacted the natural history of disease, such as in the management of early neoplasia in Barrett's esophagus, where endoscopic inspection, biopsy, and ultrasound have improved outcomes. The Japanese have used similar techniques to manage gastric cancer [27]. Similarly, surveillance in patients with inflammatory bowel disease has improved understanding of the natural history of disease by identifying and removing premalignant and early malignant lesions.

One of the monumental successes of endoscopy has undoubtedly been colorectal cancer screening. Indeed, the incidence of colorectal cancer has fallen significantly likely due to the widespread adoption of colonoscopic screening and endoscopic polypectomy [28] (Fig. 3). The ability to remove colonic adenomas-precursors of adenocarcinoma-was a major step. More recently, the use of minimally invasive techniques such as endoscopic mucosal resection and endoscopic submucosal dissection to remove large lesions has abrogated the need for routine colon resection [29]. As alluded to earlier, the development of

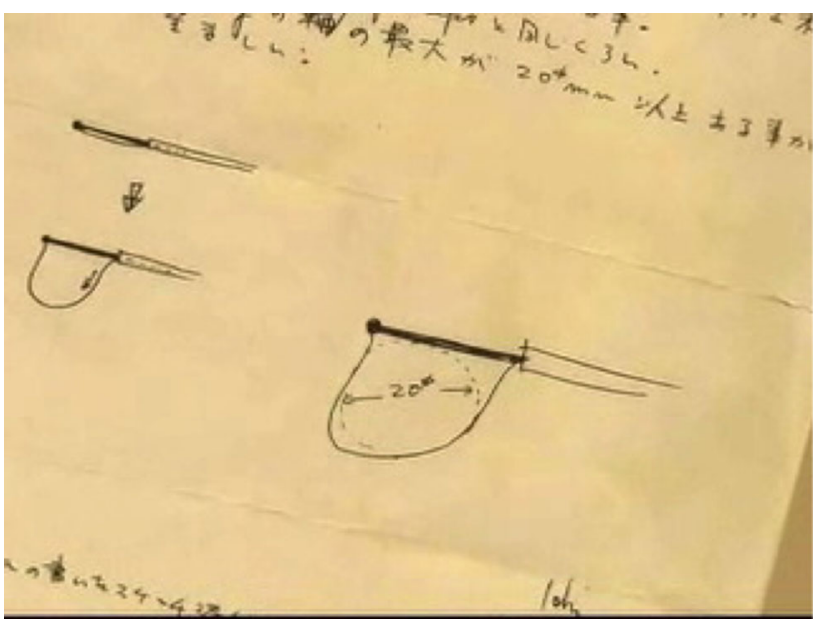

Fig. 3 Sketch of the original polyp snare which eventually would become one of the most useful endoscopic therapeutic tools (photo courtesy of the Olympus Corporation)

colonoscopes that were easier to use provided excellent images and were less traumatic for patients facilitated worldwide with dissemination of endoscopic screening.

\section{Conclusion}

The ability to perform endoscopic minimally invasive techniques is limited only by human ingenuity and the advance of technology. As recent examples, endoscopic myotomy for achalasia has again supplanted surgical methods [30]. Colonoscopes with a $360^{\circ}$ field of view have eliminated blind spots with the promise of further improving adenoma detection rates [31]. Stenting an obstructing tumor with a radiation-emitting device is entering routine practice [32]. In vivo immunohistochemistry with fluorescent-tagged antibodies promises to revolutionize the endoscopic detection of mucosal pathology [33]. The future of endoscopy, as bright as modern light sources, will continue to bring new therapies from which our patients will benefit. Without question, fiberoptic endoscopy is the singular transformative event of our lifetime.

\section{References}

1. Kaunitz JD. The fruits of fiber: the invention of the flexible fiberoptic gastroscope. Dig Dis Sci. (Epub ahead of print). doi:10. 1007/s10620-014-3339-4.

2. Hirschowitz BI. Endoscopic examination of the stomach and duodenal cap with the fiberscope. Lancet. 1961;1:1074-1078.

3. Hirschowitz BI, Luketic GC, Balint JA, Fulton WF. Early fiberscope endoscopy for upper gastrointestinal bleeding. Am J Dig Dis. 1963;8:816-825. 
4. Hirschowitz BI. Photography through the fiber gastroscope. Am J Dig Dis. 1963;8:389-395.

5. Storey DW, Bown SG, Swain CP, Salmon PR, Kirkham JS, Northfield TC. Endoscopic prediction of recurrent bleeding in peptic ulcers. $N$ Engl J Med. 1981;305:915-916.

6. Urquhart P, DaCosta R, Marcon N. Endoscopic mucosal imaging of gastrointestinal neoplasia in 2013. Curr Gastroenterol Rep. 2013;15:330.

7. Sauk J, Coron E, Kava L, et al. Interobserver agreement for the detection of Barrett's esophagus with optical frequency domain imaging. Dig Dis Sci. 2013;58:2261-2265.

8. Boerwinkel DF, Swager AF, Curvers WL, Bergman JJGHM. The clinical consequences of advanced imaging techniques in Barrett's esophagus. Gastroenterology. 2014;146:622-629.

9. Singh R, Lee SY, Vijay N, Sharma P, Uedo N. Update on narrow band imaging in of the upper gastrointestinal tract. Dig Endosc. 2014;26:144-153.

10. Graham DY. Limited value of early endoscopy in the management of acute upper gastrointestinal bleeding. Prospective controlled trial. Am J Surg. 1980;14:284-290.

11. Peterson WL, Barnett CC, Smith HJ, Allen MH, Corbett DB. Routine early endoscopy in upper-gastrointestinal-tract bleeding: a randomized, controlled trial. N Engl J Med. 1981;304:925-929.

12. Spiegel BMR, Vakil NB, Ofman JJ. Endoscopy for acute nonvariceal upper gastrointestinal tract hemorrhage: is sooner better? Arch Intern Med. 2001;161:1393-1404.

13. Fock KM, Moayyedi TN, Hunt R, et al. Asia-Pacific consensus guidelines on gastric cancer prevention. J Gastroenterol Hepatol. 2008;23:351-365.

14. Laine L. Multipolar electrocoagulation in the treatment of active upper gastrointestinal tract hemorrhage. A prospective controlled trial. N Engl J Med. 1987;316:1613-1617.

15. Cello JP, Grendell JH, Crass RA, Trunkey DD, Cobb EE, Heilbron DC. Endoscopic sclerotherapy versus portacaval shunt in patients with severe cirrhosis and variceal hemorrhage. $N$ Engl $J$ Med. 1984;311:1589-1594.

16. Sachs G, Shin JM, Munson K, Scott DR. Gastric acid-dependent diseases: a twentieth-century revolution. Dig Dis Sci. 2014;59:1358-1369.

17. Johnston GW. The rise and fall of the scalpel in peptic ulcer surgery. Ulst Med J. 1998;67:12-14.

18. Thors H, Svanes C, Thjodleifsson B. Trends in peptic ulcer morbidity and mortality in Iceland. J Clin Epidemiol. 2002; 55:681-686.

19. Shaheen NJ, Sharma P, Overholt BF, et al. Radiofrequency ablation in Barrett's esophagus with dysplasia. $N$ Engl J Med. 2009;360:2277-2288.
20. Cotton PB. Cannulation of the papilla of Vater by endoscopy and retrograde cholangiopancreatography (ERCP). Gut. 1972; 13:1014-1025.

21. Peters JH, Ellison EC, Innes JT, et al. Safety and efficiency of laparoscopic cholecystectomy. A prospective analysis of 100 initial patients. Ann Surg. 1991;213:3-12.

22. Moffatt DC, Yu BN, Yie W, Bernstein CN. Trends in utilization of diagnostic and therapeutic ERCP and cholecystectomy over the past 25 years: a population-based study. Gastrointest Endosc. 2014;79:615-622.

23. Smith AC, Dowsett JF, Russell RC, Hatfield AR, Cotton PB. Randomised trial of endoscopic stenting versus surgical bypass in malignant low bile duct obstruction. Lancet. 1994; 344:1655-1660.

24. Varadarajulu S, Bang JY, Sutton BS, Trevino JM, Christein JD, Wilcox CM. Equal efficacy of endoscopic and surgical cystogastrostomy for pancreatic pseudocyst drainage in a randomized trial. Gastroenterology. 2013;145:583-590.

25. Kahaleh M, Hernandez AJ, Tokar J, Adams RB, Shami VM, Yeaton P. Interventional EUS-guided cholangiography: evaluation of a technique in evolution. Gastrointest Endosc. 2006;64:52-59.

26. Su MY, Liu NJ, Hsu CM, Chiu CT, Chen PC, Lin CJ. Double balloon enteroscopy-the last blind-point of the gastrointestinal tract. Dig Dis Sci. 2005;50:1041-1045.

27. Sethi S, Cohen J, Thaker AM, et al. Prior capsule endoscopy improves the diagnostic and therapeutic yield of single-balloon enteroscopy. Dig Dis Sci. (Epub ahead of print). doi:10.1007/ s10620-014-3178-3.

28. Asaka M, Kato M, Sakamoto N. Roadmap to eliminate gastric cancer with Helicobacter pylori eradication and consecutive surveillance in Japan. J Gastroenterol. 2014;49:1-8.

29. Siegel R, DeSantis C, Jemal A. Colorectal cancer statistics, 2014. CA Cancer J Clin. 2014;64:104-117.

30. Ryu CB. Expanding indications for ESD: mucosal disease (upper and lower gastrointestinal tract). Gastrointest Endosc Clin N Am. 2014;24:161-167.

31. Bredenoord AJ, Rösch T, Fockens P. Peroral endoscopic myotomy for achalasia. Neurogastroenterol Motil. 2014;26:3-12.

32. Gralnek IM, Siersema PD, Halpern Z, et al. Standard forwardviewing colonoscopy versus full-spectrum endoscopy: an international, multicenter, randomized, tandem colonoscopy trial. Lancet Oncol. 2014;15:353-356.

33. Atreya R, Neumann $\mathrm{H}$, Neufert $\mathrm{C}$, et al. In vivo imaging using fluorescent antibodies to tumor necrosis factor predicts therapeutic response in Crohn's disease. Nat Med. 2014;20:313-318. 